IZA DP No. 3852

Ranking Intersecting Lorenz Curves

Rolf Aaberge

November 2008 


\title{
Ranking Intersecting Lorenz Curves
}

\author{
Rolf Aaberge \\ Statistics Norway \\ and IZA
}

\section{Discussion Paper No. 3852 \\ November 2008}

\author{
IZA \\ P.O. Box 7240 \\ 53072 Bonn \\ Germany \\ Phone: +49-228-3894-0 \\ Fax: +49-228-3894-180 \\ E-mail: iza@iza.org
}

\begin{abstract}
Any opinions expressed here are those of the author(s) and not those of IZA. Research published in this series may include views on policy, but the institute itself takes no institutional policy positions.

The Institute for the Study of Labor (IZA) in Bonn is a local and virtual international research center and a place of communication between science, politics and business. IZA is an independent nonprofit organization supported by Deutsche Post World Net. The center is associated with the University of Bonn and offers a stimulating research environment through its international network, workshops and conferences, data service, project support, research visits and doctoral program. IZA engages in (i) original and internationally competitive research in all fields of labor economics, (ii) development of policy concepts, and (iii) dissemination of research results and concepts to the interested public.
\end{abstract}

IZA Discussion Papers often represent preliminary work and are circulated to encourage discussion. Citation of such a paper should account for its provisional character. A revised version may be available directly from the author. 
IZA Discussion Paper No. 3852

November 2008

\section{ABSTRACT}

\section{Ranking Intersecting Lorenz Curves}

This paper is concerned with the problem of ranking Lorenz curves in situations where the Lorenz curves intersect and no unambiguous ranking can be attained without introducing weaker ranking criteria than first-degree Lorenz dominance. To deal with such situations two alternative sequences of nested dominance criteria between Lorenz curves are introduced. At the limit the systems of dominance criteria appear to depend solely on the income share of either the worst-off or the best-off income recipient. This result suggests two alternative strategies for increasing the number of Lorenz curves that can be strictly ordered; one that places more emphasis on changes that occur in the lower part of the income distribution and the other that places more emphasis on changes that occur in the upper part of the income distribution. Both strategies turn out to depart from the Gini coefficient; one requires higher degree of downside and the other higher degree of upside inequality aversion than what is exhibited by the Gini coefficient. Furthermore, it is demonstrated that the sequences of dominance criteria characterize two separate systems of nested subfamilies of inequality measures and thus provide a method for identifying the least restrictive social preferences required to reach an unambiguous ranking of a given set of Lorenz curves. Moreover, it is demonstrated that the introduction of successively more general transfer principles than the Pigou-Dalton principle of transfers forms a helpful basis for judging the normative significance of higher degrees of Lorenz dominance. The dominance results for Lorenz curves do also apply to generalized Lorenz curves and thus provide convenient characterizations of the corresponding social welfare orderings.

JEL Classification: D31, D63

Keywords: $\quad$ Lorenz curve, Lorenz dominance, partial orderings, Gini coefficient, rankdependent measures of inequality, generalized Gini families of inequality measures, general principles of transfers

Corresponding author:

Rolf Aaberge

Research Department

Statistics Norway

P.O. Box 8131 Dep.

$\mathrm{N}-0033$ Oslo

Norway

E-mail: rolf.aaberge@ssb.no

\footnotetext{
* This paper is forthcoming in Social Choice and Welfare. Parts of the paper were written when the author was visiting ICER in Torino. ICER and the Norwegian Research Council are gratefully acknowledged for providing financial support. I would like to thank Claudio Zoli for many stimulating discussions and a referee for helpful comments.
} 


\section{INTRODUCTION}

In empirical analyses of income distributions it is common practice to make separate comparisons of mean incomes and Lorenz curves. The Lorenz curve, which was introduced as a representation of inequality, is concerned with income shares without taking account of differences in mean incomes. By displaying the deviation of each individual income share from the income share that corresponds to perfect equality, the Lorenz curve captures the essential descriptive features of the concept of inequality. Thus, adopting the Lorenz curve as a basis for judging between income distributions means that we focus solely on distributional aspects. The widespread use of the Lorenz curve in applied work shows that focusing on distributional aspects is of interest in its own right ${ }^{2}$, irrespective of how we judge between level of mean income and degree of inequality in cases where they conflict. For welfare judgments about the trade-off between mean income and inequality we refer to Shorrocks (1983), Ebert (1987) and Lambert (1985, 1993a).

Ranking Lorenz curves in accordance with first-degree Lorenz dominance means that the higher of non-intersecting Lorenz curves is preferred. The normative significance of this criterion follows from the fact that the higher of two non-intersecting Lorenz curves can be obtained from the lower Lorenz curve by means of rank-preserving income transfers from richer to poorer individuals, which means that the criterion of first-degree Lorenz dominance is consistent with the Pigou-Dalton principle of transfers. Thus, when one Lorenz curve lies above another the higher Lorenz curve displays less inequality than the lower Lorenz curve. However, since Lorenz curves may intersect, which is often the case in applied economics, other ranking criteria than first-degree Lorenz dominance are needed to reach an unambiguous conclusion.

The standard practice for ranking intersecting Lorenz curves is to apply summary measures of inequality. However, as it may be difficult to find a single measure that gains a wide degree of support, it is of interest to search for alternative ranking criteria that are stronger than single measures of inequality and weaker than first-degree Lorenz dominance. To this end two alternative dominance criteria emerge as natural candidates; one that aggregates the Lorenz curve from below (second-degree upward Lorenz dominance) and the other that aggregates the Lorenz curve from above (second-degree downward Lorenz dominance). Since first-degree Lorenz dominance implies second-degree upward as well as downward Lorenz dominance we have that both methods preserve first-degree Lorenz dominance and thus are consistent with the Pigou-Dalton principle of transfers. However, the transfer sensitivity of these criteria differ in the sense that second-degree upward Lorenz dominance place more emphasis on transfers occurring in the lower rather than in the upper part of the income distribution, whereas seconddegree downward Lorenz dominance is most sensitive to transfers that occur in the upper part of the 
income distribution. This means that the criterion of second-degree upward Lorenz dominance requires a transfer of money from a richer to a poorer person to be more equalizing the lower it occurs in the income distribution, provided that the proportion of individuals between the donors and receivers is fixed. By contrast, the criterion of second-degree downward Lorenz dominance requires this type of transfer to be more equalizing the higher it occurs in the income distribution.

The relationship between first- and second-degree upward Lorenz dominance and measurement of inequality has been widely discussed in the economic literature. Restricting attention to distributions of equal means, Kolm (1969) and Atkinson (1970) observed that first-degree Lorenz dominance and seconddegree stochastic dominance are identical requirements, and thus recognized that the family of inequality measures derived from utilitarian social welfare functions with concave utility functions yields a characterization of the criterion of non-intersecting Lorenz curves. ${ }^{3}$ This result suggests the hypothesis that second-degree upward Lorenz dominance imposes the restriction of positive third derivative on the utility function of the utilitarian inequality measures, where second-degree upward Lorenz dominance is defined analogous to second-degree stochastic dominance. Unfortunately, this hypothesis has to be rejected since second-degree upward Lorenz dominance and third-degree stochastic dominance do not coincide. However, useful analyses of the implications of third-degree stochastic dominance on measurement of inequality and social welfare have been provided by Atkinson (2007), Shorrocks and Foster (1987), Dardanoni and Lambert (1988), Davies and Hoy (1995) and Chiu (2007), whilst Muliere and Scarsini (1989), Zoli (1999, 2002) have examined the implications of applying seconddegree Lorenz dominance as a criterion for ranking Lorenz curves.

While the majority of the results in these papers concerns the case of singly intersecting Lorenz curves the latter five papers provide results for the case of multiple crossings as well. However, the ranking criterion introduced by Davies and Hoy (1995) requires computation and comparison of the coefficient of variation for each of the actual intersections between the Lorenz curves being compared. The complexity of this approach may be considered as a drawback and makes it less attractive as a practical method for ranking Lorenz curves. By contrast, the results of Muliere and Scarsini (1989) and Zoli (1999, 2002) suggest that there may be a closer relationship between Lorenz dominance (of various degrees) and rank-dependent measures of inequality than between Lorenz dominance and utilitarian measures of inequality. This is due to the fact that rank-dependent measures of inequality, as apposed to utilitarian measures of inequality, are explicitly defined in terms of the Lorenz curve.

\footnotetext{
${ }^{2}$ See e.g. Atkinson et al. (1995) who make cross-country comparisons of Lorenz curves allowing for differences between countries in level of income and Lambert (1993b) for a discussion of applying the criterion of firstdegree Lorenz dominance as a basis for evaluating distributional effects of tax reforms.

${ }^{3}$ See Atkinson (1970) for a discussion and definition of measures of inequality derived from utilitarian welfare functions.
} 
The purpose of this paper is to explore what restrictions a set of Lorenz dominance criteria places on the weight-functions of the family of rank-dependent measures of inequality, and to provide a normative justification of these criteria by introducing appropriate general principles of transfer sensitivity. As will be demonstrated in Sections 2 and 3, second-degree Lorenz dominance forms a natural basis for the construction of two separate hierarchical sequences of partial orderings (dominance criteria), where one sequence places emphasize on changes that occur in the lower part of the Lorenz curve whereas the other places emphasize on changes that occur in the upper part of the Lorenz curve. The hierarchical and nested structure of the dominance criteria appears to be useful in empirical applications since we are allowed to identify the lowest degree of dominance required to reach unambiguous rankings of Lorenz curves. Moreover, Section 3 demonstrates that the two hierarchical sequences of Lorenz dominance criteria divide the family of rank-dependent measures of inequality into two corresponding hierarchical systems of nested subfamilies that offer two different inequality aversion profiles; one exhibits successively higher degrees of downside (positional) inequality aversion whereas the other exhibits successively higher degrees of upside (positional) inequality aversion. Since the various criteria of higher degree Lorenz dominance provide convenient computational methods, these results can be used to identify the largest subfamily of the family of rank-dependent measures of inequality and thus the least restrictive social preferences required to reach unambiguous ranking of any given set of Lorenz curves. Moreover, by considering the scaled-up version of the Lorenz curve (the generalized Lorenz curve) it can easily be demonstrated that the dominance results for Lorenz curves carry over to generalized Lorenz curves and thus provide convenient characterizations of subfamilies of rank-dependent social welfare functions. Thus, the results obtained in this paper can for example also be used as a basis for exploring how robust empirically identified optimal tax and benefit systems are with respect to choice of rank-dependent welfare function. ${ }^{4}$ Section 4 summarizes the conclusions of the paper and briefly discusses the use of the obtained results as a basis for deriving a sequence of dominance criteria for generalized Lorenz curves.

\footnotetext{
${ }^{4}$ See Moffitt (2003) for a recent review of empirical studies that focus on negative income tax and the design of welfare programs.
} 


\section{LORENZ DOMINANCE OF FIRST AND SECOND DEGREE}

The Lorenz curve $\mathrm{L}$ for a cumulative income distribution $\mathrm{F}$ with mean $\mu$ is defined by

$$
\mathrm{L}(\mathrm{u})=\frac{1}{\mu} \int_{0}^{\mathrm{u}} \mathrm{F}^{-1}(\mathrm{t}) \mathrm{dt}, 0 \leq \mathrm{u} \leq 1,
$$

where $F^{-1}(t)=\inf \{x: F(x) \geq t\}$ is the left inverse of $F$. Thus, the Lorenz curve $L(u)$ shows the share of total income received by the poorest $100 \mathrm{u}$ per cent of the population. Note that $\mathrm{F}$ can either be a discrete or a continuous distribution function. Although the former is what we actually observe, the latter often allows simpler derivation of theoretical results and is a valid large sample approximation. Thus, in most cases below $\mathrm{F}$ will be assumed to be a continuous distribution function, but the assumption of a discrete distribution function will be used where appropriate.

Under the restriction of equal mean incomes the problem of ranking Lorenz curves formally corresponds to the problem of choosing between uncertain prospects. This relationship has been utilized by e.g. Kolm (1969) and Atkinson (1970) to characterize the criterion of non-intersecting Lorenz curves in the case of distributions with equal mean incomes. This was motivated by the fact that in cases of equal mean incomes the criterion of non-intersecting Lorenz curves is equivalent to second-degree stochastic dominance ${ }^{5}$, which means that the criterion of non-intersecting Lorenz curves obeys the Pigou-Dalton principle of transfers. The Pigou-Dalton principle of transfers states that an income transfer from a richer to a poorer individual reduces income inequality, provided that their ranks in the income distribution are unchanged, and is defined formally by ${ }^{6}$

DEFINITION 2.1. (The Pigou-Dalton principle of transfers.) Consider a discrete income distribution F. A transfer $\delta>0$ from a person with income $F^{-1}(t)$ to a person with income $F^{-1}(s)$, where the transfer is assumed to be rank-preserving, is said to reduce inequality in $F$ when $s<t$ and to raise inequality in $F$ when $s>t$.

To perform inequality comparisons with Lorenz curves we can deal with distributions with equal means, or alternatively simply abandon the assumption of equal means and consider distributions of relative incomes. ${ }^{7}$ The latter approach normally forms the basis of empirical studies of income inequality.

\footnotetext{
${ }^{5}$ For a proof see Hardy, Littlewood and Polya (1934).

${ }^{6}$ Note that this definition of the Pigou-Dalton principle of transfers was proposed by Fields and Fei (1978).

${ }^{7}$ The importance of focusing on relative incomes was acknowledged already by Plato who proposed that the ratio of the top income to the bottom should be less than four to one (see Cowell, (1977)). See also Sen's (1992) discussion of relative deprivation and Smith's (1979) discussion of necessities.
} 
The standard criterion of non-intersecting Lorenz curves, called first-degree Lorenz dominance, is based on the following definition ${ }^{8}$.

DEFINITION 2.2. A Lorenz curve $L_{1}$ is said to first-degree dominate a Lorenz curve $L_{2}$ if

$$
L_{1}(u) \geq L_{2}(u) \text { for all } u \in[0,1]
$$

and the inequality holds strictly for some $u \in\langle 0,1\rangle$.

In order to examine the relationship between a set of Lorenz dominance criteria and the measurement of inequality we will rely on the family of rank-dependent measures of inequality ${ }^{9}$ defined by

$$
J_{P}(L)=1-\int_{0}^{1} P^{\prime}(u) d L(u)=1-\frac{1}{\mu} \int_{0}^{1} P^{\prime}(u) F^{-1}(u) d u
$$

where $\mathrm{L}$ is the Lorenz curve of the income distribution $\mathrm{F}$ with mean $\mu$ and the weight-function $\mathrm{P}^{\prime}$ is the derivative of a continuous, differentiable and concave function $\mathrm{P}$ defined on the unit interval where $P(0)=0$ and $P(1)=1$. To ensure that $J_{P}$ has the unit interval as its range the condition $P^{\prime}(1)=0$ is imposed on P. As demonstrated by Yaari (1988) and Aaberge (2001) the $\mathrm{J}_{\mathrm{P}}$-family represents a preference relation defined either on the class of distribution functions (F) or on the class of Lorenz curves (L), where $\mathrm{P}$ can be interpreted as a preference function of a social decision-maker. The preference function $\mathrm{P}$ assigns weights to the incomes of the individuals in accordance with their rank in the income distribution. Therefore, the functional form of $\mathrm{P}$ reveals the attitude towards inequality of a social decision-maker who employs $\mathrm{J}_{\mathrm{P}}$ to judge between Lorenz curves.

Note that the welfare economic justification for the family of rank-dependent measures defined by (2) is analogous to the justification for Atkinson's expected utility type of inequality measures. The essential differences between these two approaches for measuring inequality and social welfare arise from the so-called independence axioms. Whilst the expected utility independence axiom requires that the ordering of distributions of individual welfare is invariant with respect to identical mixing of the distributions being compared, the rank-dependent independence axiom requires that the

\footnotetext{
${ }^{8}$ Note that most analyses of Lorenz dominance apply a definition that excludes the requirement of strict inequality for some $u$.

${ }^{9}$ Mehran (1976) introduced the $\mathrm{J}_{\mathrm{P}}$-family by relying on descriptive arguments, whilst an axiomatic justification was provided by Yaari (1988). A slightly different version of $\mathrm{J}_{\mathrm{P}}$ was introduced by Piesch (1975), whereas Giaccardi (1950) considered a discrete version of $J_{\mathrm{P}}$. For alternative normative motivations of the $J_{\mathrm{P}}$-family and various subfamilies of the $\mathrm{J}_{\mathrm{P}}$-family we refer to Donaldson and Weymark (1980), Weymark (1981) and Aaberge (2001).
} 
ordering is invariant with respect to identical mixing of the inverses of the distributions being compared. For further discussion, see Yaari (1988) and Aaberge (2001).

As demonstrated by Yaari (1988), the $\mathrm{J}_{\mathrm{P}}$-family of inequality measures can be used as a basis for characterizing first-degree Lorenz dominance. For the sake of completeness the characterization result of first-degree Lorenz dominance given by Yaari (1988) is reproduced in Theorem 2.1 below, where $\mathbf{L}$ denotes the family of Lorenz curves and $\mathbf{P}_{1}$ is a class of preference functions defined by

$$
\mathbf{P}_{1}=\left\{\mathrm{P}: \mathrm{P}^{\prime} \text { and } \mathrm{P}^{\prime \prime} \text { are continuous on }[0,1], \mathrm{P}^{\prime}(\mathrm{t})>0 \text { and } \mathrm{P}^{\prime \prime}(\mathrm{t})<0 \text { for } \mathrm{t} \in\langle 0,1\rangle \text {, and } \mathrm{P}^{\prime}(1)=0\right\} \text {. }
$$

THEOREM 2.1. (Fields and Fei (1978) and Yaari (1988)). Let $L_{1}$ and $L_{2}$ be members of $L$. Then the following statements are equivalent,

(i) $\quad L_{1}$ first-degree dominates $L_{2}$

(ii) $\quad L_{1}$ can be obtained from $L_{2}$ by a sequence of Pigou-Dalton progressive transfers

(iii) $\quad L_{2}$ can be obtained from $L_{1}$ by a sequence of Pigou-Dalton regressive transfers

(iv) $J_{P}\left(L_{1}\right)<J_{P}\left(L_{2}\right)$ for all $P \in \boldsymbol{P}_{1}$

We refer to Fields and Fei (1978) for a proof of the equivalence between (i) and (ii) (and (iii)) and to Yaari (1988) for a proof of the equivalence between (i) and (iv).

Atkinson (1970) defined inequality aversion as equivalent to risk aversion in the theory of choice under uncertainty. This was motivated by the fact that the Pigou-Dalton transfer principle is identical to the condition of dominating non-intersecting Lorenz curves. Thus, we adopt the following definition.

DEFINITION 2.3. A social decision-maker that supports the Pigou-Dalton principle of transfers is said to exhibit inequality aversion.

The characterization of the condition of first-degree Lorenz dominance provided by Theorem 2.1 shows that non-intersecting Lorenz curves can be ordered without specifying further the functional form of the preference function $\mathrm{P}$ other than $\mathrm{P}$ being strictly concave. This means that $\mathrm{J}_{\mathrm{P}}$ satisfies the Pigou-Dalton principle of transfers for concave P-functions. To deal with situations where Lorenz curves intersect a weaker principle than first-degree Lorenz dominance is called for. To this end we may employ second-degree upward Lorenz dominance defined by

DEFINITION 2.4A. A Lorenz curve $L_{1}$ is said to second-degree upward dominate a Lorenz curve $L_{2}$ if 


$$
\int_{0}^{u} L_{1}(t) d t \geq \int_{0}^{u} L_{2}(t) d t \text { for all } u \in[0,1]
$$

and the inequality holds strictly for some $u \in\langle 0,1\rangle$.

The term upward dominance refers to the fact that the Lorenz curves are aggregated from below $^{10}$. The aggregated Lorenz curve can be considered as a sum of weighted income shares, where the weights decrease linearly with increasing rank of the income receiver in the income distribution. Thus, a social decision-maker who prefers the second-degree upward dominating of two intersecting Lorenz curves pays more attention to inequality in the lower than in the upper part of the income distribution. An alternative ranking criterion to second-degree upward Lorenz dominance is obtained by aggregating the Lorenz curve from above.

DEFINITION 2.4B. A Lorenz curve $L_{1}$ is said to second-degree downward dominate a Lorenz curve $L_{2}$ if

$$
\int_{u}^{1}\left(1-L_{2}(t)\right) d t \geq \int_{u}^{1}\left(1-L_{1}(t)\right) d t \text { for all } u \in[0,1]
$$

and the inequality holds strictly for some $u \in\langle 0,1\rangle$.

Note that second-degree downward as well as upward Lorenz dominance preserves firstdegree Lorenz dominance since first-degree Lorenz dominance implies second-degree upward as well as second-degree downward Lorenz dominance. Consequently, both dominance criteria are consistent with the Pigou-Dalton principle of transfers. The choice between second-degree upward and downward Lorenz dominance clarifies whether or not equalizing transfers between poorer individuals should be considered more important than those between richer individuals. A social decision-maker who favors second-degree upward Lorenz dominance would most likely prefer third-degree upward Lorenz dominance to third-degree downward Lorenz dominance, because third-degree upward Lorenz dominance places the emphasis on equalizing transfers between poorer individuals, whereas thirddegree downward Lorenz dominance places the emphasis on equalizing transfers between richer individuals.

To judge the normative significance of the criteria of second-degree upward and downward Lorenz dominance, more powerful principles than the Pigou-Dalton principle of transfers are needed. To this end Kolm (1976) introduced the principle of diminishing transfers ${ }^{11}$, which for a fixed

\footnotetext{
${ }^{10}$ Note that second-degree upward Lorenz dominance is equivalent to a normalized version of third-degree inverse stochastic dominance introduced by Muliere and Scarsini (1989).

${ }^{11}$ Denoted aversion to downside inequality by Davies and Hoy (1995).
} 
difference in income considers a transfer from a richer to a poorer person to be more equalizing the further down in the income distribution it takes place. ${ }^{12}$ As indicated by Shorrocks and Foster (1987) and Muliere and Scarsini (1989) the principle of diminishing transfers is, however, not consistent with second-degree upward Lorenz dominance. Mehran (1976) introduced an alternative version of the principle of diminishing transfers by accounting for the difference in the proportion of individuals between donors and recipients of the income transfers rather than for the difference in income. The principle introduced by Mehran (1976) proves to characterize second-degree upward Lorenz dominance. To provide a formal definition of this principle, called the principle of positional transfer sensitivity by Zoli (1999), let I be an inequality measure and let $\Delta \mathrm{I}_{\mathrm{t}}(\delta, \mathrm{h})$ denote the change in I resulting from a transfer $\delta$ from a person with income $\mathrm{F}^{-1}(\mathrm{t}+\mathrm{h})$ to a person with income $\mathrm{F}^{-1}(\mathrm{t})$ that leaves their ranks in the income distribution $F$ unchanged, where $F$ is assumed to be a discrete distribution for a finite population. Hence, $\Delta \mathrm{I}_{\mathrm{t}}(\delta, \mathrm{h})$ is a negative number for any inequality measure that obeys the Pigou-Dalton principle of transfers ${ }^{13}$. Furthermore, let $\Delta_{1} \mathrm{I}_{\mathrm{s}, \mathrm{t}}(\delta, \mathrm{h})$ be defined by

$$
\Delta_{1} \mathrm{I}_{\mathrm{s}, \mathrm{t}}(\delta, \mathrm{h})=\Delta \mathrm{I}_{\mathrm{t}}(\delta, \mathrm{h})-\Delta \mathrm{I}_{\mathrm{s}}(\delta, \mathrm{h})
$$

Since the value of $\Delta_{1} I_{s, t}(\delta, h)$ associated with a member of the $J_{P}$ - family defined by (2) either can be positive or negative, it will be useful to introduce two alternative versions of the principle of transfer sensitivity. Formal definitions of these principles are given by

DEFINITION 2.5. Consider a discrete income distribution F, an inequality measure I that obeys the Pigou-Dalton principle of transfers and rank-preserving transfers $\delta>0$ from individuals with ranks $s+h$ and $t+h$ to individuals with ranks $\mathrm{s}$ and $\mathrm{t}$ in $\mathrm{F}$. Then the inequality measure $\mathrm{I}$ is said to satisfy the principle of first-degree downside [upside] positional transfer sensitivity (first-degree DPTS [UPTS]) if $\Delta_{1} I_{s, t}(\delta, h)>0$ when $s<t\left[\Delta_{1} I_{s, t}(\delta, h)<0\right.$ when $\left.s<t\right]$.

Figure1. Illustration of DPTS and UPTS

\footnotetext{
${ }^{12}$ For a formal definition, see Kolm (1976).

${ }^{13}$ For convenience the dependence of I on F is suppressed in the notation for I.
} 


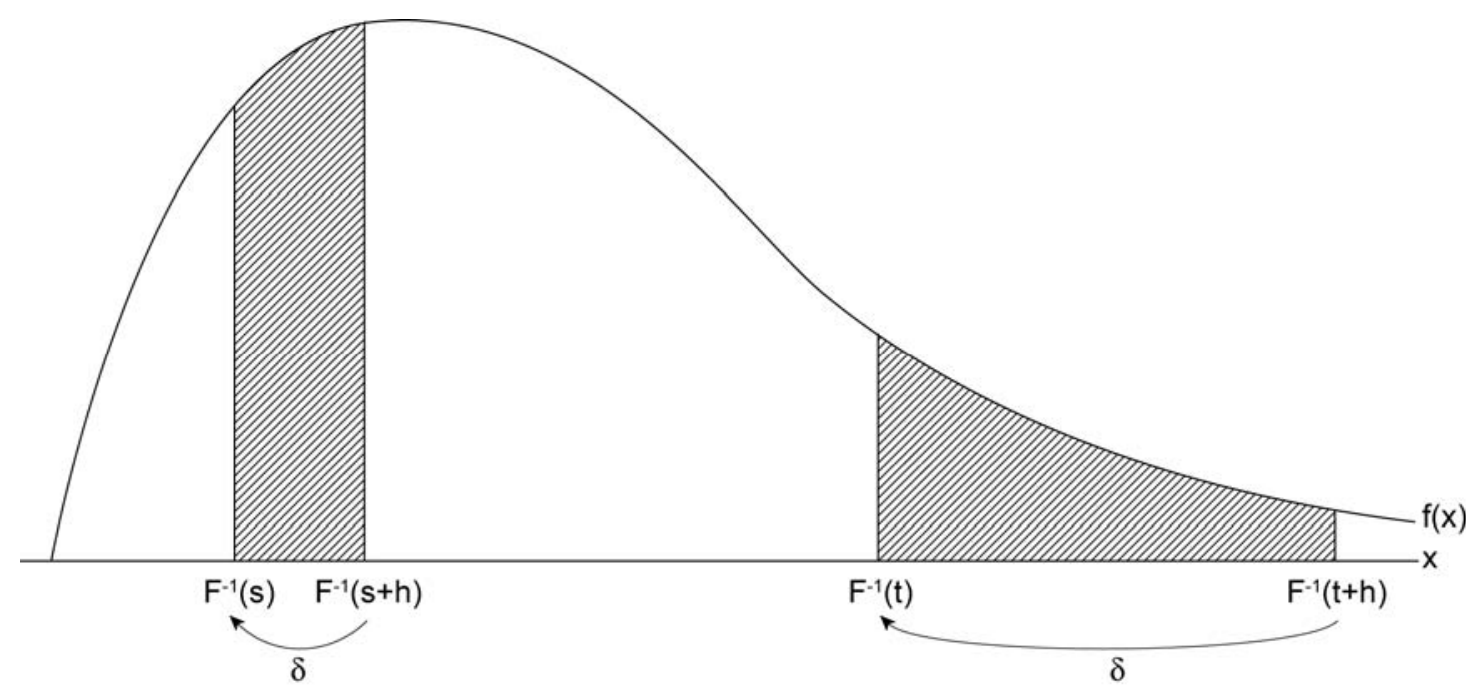

Note that the shaded areas of Figure 1 for the density $\mathrm{f}$ are identical, which means that the number of people located between $\mathrm{F}^{-1}(\mathrm{~s}+\mathrm{h})$ and $\mathrm{F}^{-1}(\mathrm{~s})$ is equal to the number of people located between $\mathrm{F}^{-1}(\mathrm{t}+\mathrm{h})$ and $\mathrm{F}^{-1}(\mathrm{t})$. Since income distributions normally are skewed to the right this means, as is illustrated by Figure 1, that the income difference between the donor and receiver under the DPTS as well as under the UPTS is smaller in the lower than in the upper part of the income distribution.

Mehran (1976) demonstrated that $\mathrm{J}_{\mathrm{P}}$ defined by (2) satisfies first-degree DPTS if and only if $\mathrm{P}^{\prime \prime \prime}(\mathrm{t})>0{ }^{14}$. Moreover, as stated in Theorem 2.2A below dominance for all $\mathrm{J}_{\mathrm{P}}$ that satisfy the Pigou-Dalton principle of transfers and the first-degree DPTS proves to be equivalent to the condition of second-degree upward Lorenz dominance.

Let $\mathbf{P}_{12}^{*}$ be a family of preference functions related to $\mathrm{J}_{\mathrm{P}}$ and defined by $\mathbf{P}_{12}^{*}=\left\{\mathrm{P}: \mathrm{P} \in \mathbf{P}_{1}, \mathrm{P}^{\prime \prime \prime}\right.$ is continuous on $[0,1]$ and $\mathrm{P}^{\prime \prime \prime}(\mathrm{t})>0$ for $\left.\mathrm{t} \in\langle 0,1\rangle\right\}$.

The following result provides a characterization of second-degree upward Lorenz dominance. $^{15}$

THEOREM 2.2A. Let $L_{1}$ and $L_{2}$ be members of $\boldsymbol{L}$. Then the following statements are equivalent, (i) $\quad L_{1}$ second-degree upward dominates $L_{2}$

\footnotetext{
${ }^{14}$ Aaberge (2000) demonstrated that $\mathrm{J}_{\mathrm{P}}$ defined by (2) satisfies Kolm's principle of diminishing transfers under conditions that depend on the shape of the preference function $\mathrm{P}$ as well as on the shape of the income distribution F.

${ }^{15}$ In cases of equal means Proposition 2 of Zoli (1999) and Theorem 2.2A yield identical results.
} 


$$
J_{P}\left(L_{1}\right)<J_{P}\left(L_{2}\right) \text { for all } P \in \boldsymbol{P}_{12}^{*}
$$

(iii) $\quad J_{P}\left(L_{1}\right)<J_{P}\left(L_{2}\right)$ for all $P \in \boldsymbol{P}_{1}$ being such that $J_{P}$ obeys the principle of first-degree DPTS. (Proof in Appendix).

To ensure equivalence between second-degree upward Lorenz dominance and $\mathrm{J}_{\mathrm{P}}$-measures as decision criteria, Theorem 2.2A shows that it is necessary to restrict the preference functions $P$ to be concave with positive third derivatives. If, by contrast, $\mathrm{P}$ has negative third derivative, then Theorem 2.2B yields the downward dominance analogy to Theorem 2.2A.

Let $\mathbf{P}_{22}^{*}$ be a family of preference functions related to $\mathrm{J}_{\mathrm{P}}$ and defined by

$$
\mathbf{P}_{22}^{*}=\left\{\mathrm{P}: \mathrm{P} \in \mathbf{P}_{1}, \mathrm{P}^{\prime \prime \prime} \text { is continuous on }[0,1] \text { and } \mathrm{P}^{\prime \prime \prime}(\mathrm{t})<0 \text { for } \mathrm{t} \in\langle 0,1\rangle\right\} \text {. }
$$

THEOREM 2.2B. Let $L_{1}$ and $L_{2}$ be members of $\boldsymbol{L}$. Then the following statements are equivalent,

(i) $\quad L_{1}$ second-degree downward dominates $L_{2}$

(ii) $\quad J_{P}\left(L_{1}\right)<J_{P}\left(L_{2}\right)$ for all $P \in \boldsymbol{P}_{22}^{*}$

(iii) $\quad J_{P}\left(L_{1}\right)<J_{P}\left(L_{2}\right)$ for all $P \in \boldsymbol{P}_{1}$ being such that $J_{P}$ obeys the principle of first-degree UPTS.

(Proof in Appendix).

REMARK. It follows from the proofs of Theorem $2.2 \mathrm{~A}$ and $2.2 \mathrm{~B}$ that the condition $\mathrm{P}^{\prime \prime}(\mathrm{t})<0$ for all $\mathrm{t} \in\langle 0,1\rangle$ can be relaxed and replaced by the conditions $\mathrm{P}^{\prime \prime}(1) \leq 0$ and $\mathrm{P}^{\prime \prime}(0) \leq 0$, respectively. Accordingly, the equivalence between (ii) and (iii) in Theorem 2.2A means that any $\mathrm{J}_{\mathrm{P}}$ with $\mathrm{P}^{\prime \prime \prime}(\mathrm{t})>0$ obeys the first-degree DPTS independent of whether $\mathrm{P}^{\prime \prime}(\mathrm{t})$ is larger or smaller than 0 for $t \in\langle 0,1\rangle \cdot{ }^{16} \mathrm{~A}$ similar remark can be made for Theorem 2.2B. Thus, any $\mathrm{J}_{\mathrm{P}}$ with $\mathrm{P}^{\prime \prime \prime}(\mathrm{t})<0$ obeys the first-degree UPTS. However, the relevance of using measures of inequality that do not obey the Pigou-Dalton of transfers $\left(\mathrm{P}^{\prime \prime}(\mathrm{t})>0\right)$ might be questioned.

An inequality averse social decision-maker that supports the criterion of second-degree upward Lorenz dominance will act in line with the principle of first-degree DPTS and assign more weight to changes that take place in the lower part of the Lorenz curve than to changes that occur in the upper part of the Lorenz curve. By contrast, the criterion of second-degree downward Lorenz dominance emphasizes changes that occur in the upper part of the Lorenz curve. Thus, a social decision-maker that exhibits inequality aversion and employs the criterion of second-degree downward Lorenz dominance will act in favor of the Pigou-Dalton principle of transfers and the 
principle of first-degree UPTS. To characterize social preferences of these types we adopt the following definition ${ }^{17}$.

DEFINITION 2.6. An inequality averse social decision-maker that supports the Pigou-Dalton principle of transfers and the principle of first-degree DPTS (UPTS) is said to exhibit downside (upside) positional inequality aversion of first-degree.

Theorems 2.2A and 2.2B demonstrate that the criteria of second-degree upward and downward Lorenz dominance can be used to divide $\mathrm{J}_{\mathrm{P}}$-measures into wide families of inequality measures that differ in the measures' sensitivity to changes (transfers) in the lower or upper part of the Lorenz curve. Members of the family $\left\{\mathrm{J}_{\mathrm{P}}: \mathrm{P} \in \mathbf{P}_{12}^{*}\right\}$ give more weight to changes that take place lower down in the Lorenz curve, whereas members of the family $\left\{\mathrm{J}_{\mathrm{P}}: \mathrm{P} \in \mathbf{P}_{22}^{*}\right\}$ give more weight to changes higher up in the Lorenz curve. Note that $P(t)=2 t-t^{2}$, the P-function that corresponds to the Gini coefficient, is neither included in $\mathbf{P}_{12}^{*}$ nor in $\mathbf{P}_{22}^{*}$. Since $\mathrm{P}^{\prime \prime \prime}(\mathrm{t})=0$ for all $\mathrm{t}$, the Gini coefficient neither preserves second-degree upward Lorenz dominance nor second-degree downward Lorenz dominance. ${ }^{18}$ Thus, the suggestion of Muliere and Scarsini (1989) that the Gini coefficient is coherent with second-degree upward Lorenz dominance requires a definition of second-degree Lorenz dominance that abandons the condition of strict inequality (for some $u \in\langle 0,1\rangle$ ).

\section{LORENZ DOMINANCE OF I ${ }^{\text {th }}-$ DEGREE}

Since situations where second-degree (upward or downward) Lorenz dominance does not provide unambiguous ranking of Lorenz curves may arise, it will be useful to introduce weaker dominance criteria than second-degree Lorenz dominance. To this end we will introduce two hierarchical sequences of nested Lorenz dominance criteria; one departs from second-degree upward Lorenz dominance and the other from second-degree downward Lorenz dominance. As explained in Section 2, the choice between seconddegree upward and downward Lorenz dominance clarifies whether focus is turned to changes that take place in the lower or upper part of the income distribution. Thus, a person who favors second-degree upward Lorenz dominance would most likely prefer third-degree and higher degrees of upward Lorenz dominance to third-degree and higher degrees of downward Lorenz dominance. Conversely, when the value judgment of a person is consistent with the criterion of second-degree downward Lorenz

\footnotetext{
${ }^{16}$ See Chateauneuf et al. (2002) for an alternative proof of this result.

${ }^{17}$ For an alternative definition of downside inequality aversion see Chiu (2007).

${ }^{18}$ Aaberge (2000) gave an alternative interpretation of this property by demonstrating that the Gini coefficient attaches an equal weight to a given transfer irrespective of where it takes place in the income distribution, as long as the income transfer occurs between individuals with the same difference in ranks.
} 
dominance, higher degrees of downward Lorenz dominance are likely more acceptable than higher degrees of upward Lorenz dominance

As will become evident below it is convenient to use the following notation,

$$
\begin{gathered}
\mathrm{L}^{2}(\mathrm{u})=\int_{0}^{\mathrm{u}} \mathrm{L}(\mathrm{t}) \mathrm{dt}=\frac{1}{\mu} \int_{0}^{\mathrm{u}}(\mathrm{u}-\mathrm{t}) \mathrm{F}^{-1}(\mathrm{t}) \mathrm{dt}, \quad 0 \leq \mathrm{u} \leq 1, \\
\mathrm{~L}^{\mathrm{i}+1}(\mathrm{u})=\int_{0}^{\mathrm{u}} \mathrm{L}^{\mathrm{i}}(\mathrm{t}) \mathrm{dt}, \quad 0 \leq \mathrm{u} \leq 1, \mathrm{i}=2,3, \ldots,
\end{gathered}
$$

and

$$
\begin{gathered}
\tilde{L}^{2}(\mathrm{u})=\int_{\mathrm{u}}^{1}(1-\mathrm{L}(\mathrm{t})) \mathrm{dt}=\frac{1}{\mu} \int_{\mathrm{u}}^{1}(\mathrm{t}-\mathrm{u}) \mathrm{F}^{-1}(\mathrm{t}) \mathrm{dt}, 0 \leq \mathrm{u} \leq 1, \\
\tilde{\mathrm{L}}^{\mathrm{i}+1}(\mathrm{u})=\int_{\mathrm{u}}^{1} \tilde{\mathrm{L}}^{\mathrm{i}}(\mathrm{t}) \mathrm{dt}, 0 \leq \mathrm{u} \leq 1, \mathrm{i}=2,3, \ldots .
\end{gathered}
$$

Now, using integration by parts, we obtain the following alternative expressions for $\mathrm{L}^{\mathrm{i}+1}$ and $\tilde{\mathrm{L}}^{\mathrm{i}+1}$, respectively,

$$
L^{i+1}(u)=\frac{1}{(i-1) !} \int_{0}^{u}(u-t)^{i-1} L(t) d t=\frac{1}{i ! \mu} \int_{0}^{u}(u-t)^{i} F^{-1}(t) d t, \quad i=2,3, \ldots
$$

and

$$
\tilde{\mathrm{L}}^{\mathrm{i}+1}(\mathrm{u})=\frac{1}{(\mathrm{i}-1) !} \int_{u}^{1}(\mathrm{t}-\mathrm{u})^{\mathrm{i}-1}(1-\mathrm{L}(\mathrm{t})) \mathrm{dt}=\frac{1}{\mathrm{i} ! \mu} \int_{u}^{1}(\mathrm{t}-\mathrm{u})^{\mathrm{i}} \mathrm{F}^{-1}(\mathrm{t}) \mathrm{dt}, \quad \mathrm{i}=2,3, \ldots
$$

It is easily verified that $\mathrm{L}^{\mathrm{i}+1}(1)$ defined by (6) is a linear transformation of a measure of inequality that belongs to the extended Gini family of inequality measures ${ }^{19}\left\{G_{i}: i \geq 1\right\}$,

$$
L^{i+1}(1)=\frac{1}{(i+1) !}\left(1-G_{i}(L)\right), i=1,2, \ldots
$$

where

${ }^{19}$ The extended Gini family of inequality measures was introduced by Donaldson and Weymark (1980) and Yitzhaki (1983). 


$$
G_{i}(L)=1-i(i+1) \int_{0}^{1}(1-u)^{i-1} L(u) d u=\frac{1}{\mu} \int_{0}^{\infty}(1-F(x))\left(1-(1-F(x))^{i}\right) d x, i \geq 1 .
$$

Moreover, from the definition (7) of $\tilde{\mathrm{L}}$ we get that

$$
\tilde{\mathrm{L}}^{\mathrm{i}+1}(0)=\frac{1}{(\mathrm{i}+1) !}\left(\mathrm{iD}_{\mathrm{i}}(\mathrm{L})+1\right), \mathrm{i}=1,2, \ldots
$$

where

$$
D_{i}(L)=1-(i+1) \int_{0}^{1} u^{i-1} L(u) d u=\frac{1}{\mu i} \int_{0}^{\infty} F(x)\left(1-F^{i}(x)\right) d x, i=1,2, \ldots
$$

and $\left\{D_{i}: i=1,2, \ldots\right\}$ is an alternative "generalized" Gini family of inequality measures denoted the Lorenz family of inequality measures ${ }^{20}$, where $D_{1}=G_{1}$ is equal to the Gini coefficient.

As was demonstrated by Aaberge (2000) there is a one-to-one correspondence between subfamilies of the extended Gini and the Lorenz families of inequality measures shown by the following equation

$$
\mathrm{G}_{\mathrm{i}}(\mathrm{L})=1+(\mathrm{i}+1) \sum_{\mathrm{k}=1}^{\mathrm{i}}(-1)^{\mathrm{k}}\left(\begin{array}{l}
\mathrm{i} \\
\mathrm{k}
\end{array}\right) \frac{\mathrm{k}}{\mathrm{k}+1}\left(1-\mathrm{D}_{\mathrm{k}}(\mathrm{L})\right), \quad \mathrm{i}=1,2, \ldots
$$

Thus, the extended Gini subfamily $\left\{G_{i}(L): i=1,2, \ldots, r\right\}$ is uniquely determined by the corresponding Lorenz subfamily $\left\{D_{i}(L): i=1,2, \ldots, r\right\}$ for any integer $r$.

Expressions (6) and (7) show that $\mathrm{L}^{\mathrm{i}+1}$ places more weight on changes in the lower and $\tilde{\mathrm{L}}^{\mathrm{i}+1}$ on changes in the upper part of the Lorenz curve as i increases.

As generalizations of Definitions 2.4A and 2.4B we introduce the notions of $i^{\text {th }}$-degree upward and downward Lorenz dominance ${ }^{21}$. Note that subscripts $i$ and $j$ in the notation $L_{j}^{i}$ and $\tilde{L}_{j}^{i}$ used below refer to dominance of $i^{\text {th }}$-degree for Lorenz curve $L_{j}$ and that $L_{j}^{1}$ is the Lorenz curve $L_{j}$ and $\tilde{L}_{j}^{1}=1-L_{j}$.

DEFINITION 3.1A. A Lorenz curve $L_{1}$ is said to $\boldsymbol{i}^{\text {th }}$-degree upward dominate a Lorenz curve $L_{2}$ if

$$
L_{1}^{i}(u) \geq L_{2}^{i}(u) \text { for all } u \in[0,1]
$$

\footnotetext{
${ }^{20}$ The Lorenz family of inequality measures was introduced by Aaberge (2000) and proves to be a subclass of the "illfare-ranked single-series Ginis" discussed by Donaldson and Weymark (1980) and Bossert (1990).

${ }^{21}$ A similar definition of $i^{\text {th }}$ degree (upward) inverse stochastic dominance was introduced by Muliere and Scarsini (1989). Note that Definitions 3.1A and 3.1B do not require any restrictions on the Lorenz curves (or the distribution functions) and thus differ in this sense from the definitions of stochastic dominance proposed by Whitmore (1970) and Chew (1983).
} 
and the inequality holds strictly for some $u \in\langle 0,1\rangle$.

DEFINITION 3.1B. A Lorenz curve $L_{1}$ is said to $i^{\text {th }}$-degree downward dominate a Lorenz curve $L_{2}$ if

$$
\tilde{L}_{2}^{i}(u) \geq \tilde{L}_{1}^{i}(u) \text { for all } u \in[0,1]
$$

and the inequality holds strictly for some $u \in\langle 0,1\rangle$.

Note that $(\mathrm{i}+1)^{\text {th }}$-degree upward and downward Lorenz dominance are less restrictive dominance criteria than $\mathrm{i}^{\text {th }}$-degree upward and downward Lorenz dominance and thus can prove to be useful decision criteria in situations where $i^{\text {th }}$-degree dominance does not yield an unambiguous ranking of Lorenz curves.

It follows from the definitions (6) and (7) of $\mathrm{L}^{\mathrm{i}}$ and $\tilde{\mathrm{L}}^{\mathrm{i}}$ that

$$
\mathrm{L}_{1}^{\mathrm{i}}(\mathrm{u}) \geq \mathrm{L}_{2}^{\mathrm{i}}(\mathrm{u}) \text { for all } \mathrm{u} \text { implies } \mathrm{L}_{1}^{\mathrm{i}+1}(\mathrm{u}) \geq \mathrm{L}_{2}^{\mathrm{i}+1}(\mathrm{u}) \text { for all } \mathrm{u} \text {, }
$$

and that

$$
\tilde{\mathrm{L}}_{2}^{\mathrm{i}}(\mathrm{u}) \geq \tilde{\mathrm{L}}_{1}^{\mathrm{i}}(\mathrm{u}) \text { for all } \mathrm{u} \text { implies } \tilde{\mathrm{L}}_{2}^{\mathrm{i}+1}(\mathrm{u}) \geq \tilde{\mathrm{L}}_{1}^{\mathrm{i}+1}(\mathrm{u}) \text { for all } \mathrm{u} \text {, }
$$

which means that $(i+1)^{\text {th }}$-degree upward Lorenz dominance preserves $i^{\text {th }}$-degree upward Lorenz dominance and that $(i+1)^{\text {th }}$-degree downward Lorenz dominance preserves $i^{\text {th }}$-degree downward Lorenz dominance.

Thus, the various degrees of upward and downward Lorenz dominance form two separate sequences of nested dominance criteria, which turn out to be useful for dividing the $\mathrm{J}_{\mathrm{P}}$-family of inequality measures into nested subfamilies. To this end it will be convenient to introduce the following notation. Let $\mathrm{P}^{(\mathrm{j})}$ denote the $\mathrm{j}^{\text {th }}$ derivative of $\mathrm{P}$ and let $\mathbf{P}_{1 \mathrm{i}}, \mathbf{P}_{1 \mathrm{i}}^{*}, \mathbf{P}_{1 \mathrm{i}}^{* * *}, \mathbf{P}_{1 \mathrm{i}}^{* * *}, \mathbf{P}_{2 \mathrm{i}}, \mathbf{P}_{2 \mathrm{i}}^{*}, \mathbf{P}_{2 \mathrm{i}}^{* * *}, \mathbf{P}_{2 \mathrm{i}}^{* * *}$ be families of preference functions defined by

$$
\begin{gathered}
\mathbf{P}_{1 \mathrm{i}}=\left\{\mathrm{P}: \mathrm{P} \in \mathbf{P}_{1}, \mathrm{P}^{(\mathrm{i}+1)} \text { is continuous on }[0,1] \text { and } \mathrm{P}^{(\mathrm{j})}(1)=0, \mathrm{j}=2,3, \ldots, \mathrm{i}\right\}, \\
\mathbf{P}_{1 \mathrm{i}}^{*}=\left\{\mathrm{P}: \mathrm{P} \in \mathbf{P}_{1 \mathrm{i}} \text { and }(-1)^{\mathrm{j}} \mathrm{P}^{(\mathrm{j}+1)}(\mathrm{t})>0 \text { for } \mathrm{t} \in\langle 0,1\rangle, \mathrm{j}=1,2, \ldots, \mathrm{i}\right\}, \\
\mathbf{P}_{1 \mathrm{i}}^{* *}=\left\{\mathrm{P}: \mathrm{P} \in \mathbf{P}_{1 \mathrm{i}} \text { and }(-1)^{\mathrm{i}} \mathrm{P}^{(\mathrm{i}+1)}(\mathrm{t})>0 \text { for } \mathrm{t} \in\langle 0,1\rangle\right\},
\end{gathered}
$$




$$
\mathbf{P}_{1 i}^{* * *}=\left\{\mathrm{P}: \mathrm{P} \in \mathbf{P}_{1}, \mathrm{P}^{(\mathrm{i}+1)} \text { is continuous on }[0,1],(-1)^{\mathrm{i}} \mathrm{P}^{(\mathrm{i}+1)}(\mathrm{t})>0 \text { for } \mathrm{t} \in\langle 0,1\rangle \text { and }(-1)^{\mathrm{j}-1} \mathrm{P}^{(\mathrm{j})}(1) \geq 0, \mathrm{j}=2,3, \ldots, \mathrm{i}\right\} \text {, }
$$

$$
\mathbf{P}_{2 \mathrm{i}}=\left\{\mathrm{P}: \mathrm{P} \in \mathbf{P}_{1}, \mathrm{P}^{(\mathrm{i}+1)} \text { is continuous on }[0,1] \text { and } \mathrm{P}^{(\mathrm{j})}(0)=0, \mathrm{j}=2,3, \ldots, \mathrm{i}\right\} \text {, }
$$

$$
\mathbf{P}_{2 \mathrm{i}}^{*}=\left\{\mathrm{P}: \mathrm{P} \in \mathbf{P}_{2 \mathrm{i}} \text { and } \mathrm{P}^{(\mathrm{j}+1)}(\mathrm{t})<0 \text { for } \mathrm{t} \in\langle 0,1\rangle, \mathrm{j}=1,2, \ldots, \mathrm{i}\right\} \text {, }
$$

$$
\mathbf{P}_{2 \mathrm{i}}^{* *}=\left\{\mathrm{P}: \mathrm{P} \in \mathbf{P}_{2 \mathrm{i}} \text { and } \mathrm{P}^{(\mathrm{i}+1)}(\mathrm{t})<0 \text { for } \mathrm{t} \in\langle 0,1\rangle\right\} \text {, }
$$

$$
\mathbf{P}_{2 i}^{* * *}=\left\{\mathrm{P}: \mathrm{P} \in \mathbf{P}_{1}, \mathrm{P}^{(\mathrm{i}+1)} \text { is continuous on }[0,1], \mathrm{P}^{(\mathrm{i}+1)}(\mathrm{t})<0 \text { for } \mathrm{t} \in\langle 0,1\rangle \text { and } \mathrm{P}^{(\mathrm{j})}(0) \leq 0, \mathrm{j}=2,3, \ldots, \mathrm{i}\right\} \text {, }
$$

respectively. Note that $\mathbf{P}_{1 \mathrm{i}}^{*} \subset \mathbf{P}_{1 \mathrm{i}}^{* * *} \subset \mathbf{P}_{1 \mathrm{i}}^{* * * *}$ and $\mathbf{P}_{2 \mathrm{i}}^{*} \subset \mathbf{P}_{2 \mathrm{i}}^{* * *} \subset \mathbf{P}_{2 \mathrm{i}}^{* * * *}$.

The subfamilies of the $\mathrm{J}_{\mathrm{P}}$-family formed by $\mathbf{P}_{1 \mathrm{i}}^{* * *}$ and $\mathbf{P}_{2 \mathrm{i}}^{* * *}$ are characterized by the following theorems.

THEOREM 3.1A. Let $L_{1}$ and $L_{2}$ be members of $\boldsymbol{L}$. Then the following statements are equivalent,

(i) $\quad L_{1} i^{\text {th }}$-degree upward dominates $L_{2}$.

(ii) $\quad J_{P}\left(L_{1}\right)<J_{P}\left(L_{2}\right)$ for all $P \in \boldsymbol{P}_{1 i}^{* *}$.

(Proof in Appendix).

THEOREM 3.1B. Let $L_{1}$ and $L_{2}$ be members of $\boldsymbol{L}$. Then the following statements are equivalent,

(i) $\quad L_{1} i^{\text {th }}$-degree downward dominates $L_{2}$

(ii) $\quad J_{P}\left(L_{1}\right)<J_{P}\left(L_{2}\right)$ for all $P \in \boldsymbol{P}_{2 i}^{* *}$.

(Proof in Appendix).

The set of Lorenz dominance criteria offers convenient computational methods for applied work. As is demonstrated by Theorems 3.1A and 3.1B this approach is particular attractive since it provides identification of the restrictions on the preference function $\mathrm{P}$ that are needed to reach unambiguous rankings of Lorenz curves. ${ }^{22}$ Note that Theorem 3.1A can be employed for the extended Gini family since the inequality measure $G_{k}$ satisfies the conditions $P^{j}(1)=0, j=2,3, \ldots, k$, whereas

\footnotetext{
${ }^{22}$ Muliere and Scarsini (1989) provided a characterization of $i^{\text {th }}$-degree (upward) inverse stochastic dominance in terms of order conditions for a particular subfamily of $\mathbf{P}_{1 \mathrm{i}}^{*}$. Note, however, that their result cannot be used as a basis for identifying what restrictions $\mathrm{i}^{\text {th }}$-degree upward Lorenz dominance (inverse stochastic dominance) impose on the preference function P.
} 
Theorem 3.1B can be employed for the Lorenz family of inequality measures since the measure $D_{k}$ satisfies the conditions $\mathrm{P}^{(\mathrm{j})}(0)=0, \mathrm{j}=2,3, \ldots, \mathrm{k}$.

To judge the normative significance of $\mathrm{i}^{\text {th }}$-degree upward and downward Lorenz dominance, it appears helpful to strengthen the principles of first-degree downside and upside positional transfer sensitivity to be more sensitive to transfers that take place lower down (higher up) in the income distribution. To this end it will be useful to introduce the following notation. Let $\Delta_{2} \mathrm{I}_{\mathrm{s}, \mathrm{t}}\left(\delta, \mathrm{h}_{1}, \mathrm{~h}_{2}\right)$ be defined by

$$
\Delta_{2} I_{s, t}\left(\delta, h_{1}, h_{2}\right)=\Delta_{1} I_{s, t}\left(\delta, h_{1}\right)-\Delta_{1} I_{s+h_{2}, t+h_{2}}\left(\delta, h_{1}\right)
$$

where $\Delta_{1} I_{s, t}(\delta, h)$ is defined by (3).

DEFINITION 3.3. Consider a discrete income distribution F, an inequality measure I that obeys the first-degree DPTS [UPTS], and rank-preserving transfers $\delta>0$ from individuals with ranks $s+h_{1}$, $s+h_{1}+h_{2}, t+h_{1}$, and $t+h_{1}+h_{2}$ respectively to individuals with ranks $s, s+h_{2}, t$ and $t+h_{2}$ in $F$. Then $I$ is said to satisfy the principle of second-degree downside [upside] positional transfer sensitivity, the second-degree DPTS [UPTS] , if

$$
\Delta_{2} I_{s, t}\left(\delta, h_{1}, h_{2}\right)>0 \text { when } s<t\left[\Delta_{2} I_{s, t}\left(\delta, h_{1}, h_{2}\right)>0 \text { when } s<t\right] \text {. }
$$

Note that $\mathrm{i}^{\text {th }}$-degree DPTS can be considered as an alternative to $\mathrm{i}^{\text {th }}$-degree transfer principle introduced by Fishburn and Willig (1984). ${ }^{23}$

Observe that $\Delta_{1} \mathrm{I}_{\mathrm{s}, \mathrm{t}}<0$ for any $\mathrm{s}<\mathrm{t}$ when I obeys the first-degree UPTS. Since the principle of second-degree UPTS is meant to strengthen the principle of first-degree UPTS, it follows from (13) that this is obtained when $\Delta_{2} I_{s, t}>0$ for $\mathrm{s}<\mathrm{t}$. Thus, we can only discern between second-degree DPTS and second-degree UPTS if these principles are required to be linked to first-degree DPTS and first-degree UPTS, respectively. When a sequence of first-degree DPTS [UPTS] transfers is valued more the lower down (higher up) the sequence of the transfers occurs, the sequence of transfers is made in line with the principle of second-degree downside [upside] positional transfer sensitivity. To provide a formal definition of $(\mathrm{i}-1)^{\text {th }}$-degree DPTS [UPTS] it is convenient to introduce the notation $\Delta_{\mathrm{i}} \mathrm{I}_{\mathrm{s}, \mathrm{t}}\left(\delta, \mathrm{h}_{1}, \mathrm{~h}_{2}, \ldots, \mathrm{h}_{\mathrm{i}}\right)$ defined by

\footnotetext{
${ }^{23}$ Fishburn and Willig (1984) introduced an extension of Kolm’s principle of diminishing transfers to higherorder transfer principles and demonstrated that these principles are associated to higher orders of (upward) stochastic dominance.
} 


$$
\Delta_{\mathrm{i}} \mathrm{I}_{\mathrm{s}, \mathrm{t}}\left(\delta, \mathrm{h}_{1}, \mathrm{~h}_{2}, \ldots, \mathrm{h}_{\mathrm{i}}\right)=\Delta_{\mathrm{i}-1} \mathrm{I}_{\mathrm{s}, \mathrm{t}}\left(\delta, \mathrm{h}_{1}, \mathrm{~h}_{2}, \ldots, \mathrm{h}_{\mathrm{i}-1}\right)-\Delta_{\mathrm{i}-1} \mathrm{I}_{\mathrm{s}+\mathrm{h}_{\mathrm{i}}, \mathrm{t}+\mathrm{h}_{\mathrm{i}}}\left(\delta, \mathrm{h}_{1}, \mathrm{~h}_{2}, \ldots, \mathrm{h}_{\mathrm{i}-1}\right), \mathrm{i}=3,4, \ldots
$$

DEFINITION 3.4. Consider a discrete income distribution F, an inequality measure I that obeys the $(i-1)^{\text {th }}$-degree DPTS [UPTS], and rank-preserving transfers $\delta$ from individuals with ranks $s+h_{1}$, $s+h_{1}+h_{2}, \ldots, s+h_{1}+h_{i}, \ldots, \quad s+h_{1}+h_{2}+\ldots+h_{i}, \quad t+h_{1}, \quad t+h_{1}+h_{2}, \ldots, t+h_{1}+h_{i}, \ldots, \quad t+h_{1}+h_{2}+\ldots+h_{i}$ respectively to individuals with ranks $s+h_{2}, \ldots, s+h_{i}, \ldots, s+h_{2}+h_{3}+\ldots+h_{i}, t, t+h_{2}, \ldots, t+h_{i}, \ldots, t+h_{2}+h_{3}+\ldots+h_{i}$ in F. Then I is said to satisfy the principle of $i^{\text {th }}$-degree downside [upside] positional transfer sensitivity, the $i^{\text {th }}$-degree DPTS [UPTS], if $\quad \Delta_{i} I_{s, t}\left(\delta, h_{1}, h_{2}, \ldots, h_{i}\right)>0$ when $s<t\left[(-1)^{i} \Delta_{i} I_{s, t}\left(\delta, h_{1}, h_{2}, \ldots, h_{i}\right)>0\right.$ when $\left.s<t\right]$.

The motivation for introducing the principle of $(\mathrm{i}-1)^{\text {th }}$-degree DPTS [UPTS] was to strengthen the principle of $(i-2)^{\text {th }}$-degree DPTS [UPTS]. Hence, if a measure of inequality satisfies the principle of $(\mathrm{i}-1)^{\text {th }}$-degree DPTS [UPTS], then it also satisfies the Pigou-Dalton principle of transfers and the principles of DPTS [UPTS] of each degree up to i - 2. Thus, the general transfer principles DPTS [UPTS] give increasing weights to transfers at the lower [upper] part of the income distribution as i increases. As stated in Theorems 3.2A and 3.2B, support of the principle of $(\mathrm{i}-1)^{\text {th }}$ degree DPTS is equivalent to be in favor of the criterion of $i^{\text {th }}$-degree upward Lorenz dominance, whereas support of the principle of $(i-1)^{\text {th }}$-degree UPTS is equivalent to be in favor of $i^{\text {th }}$-degree downward Lorenz dominance.

THEOREM 3.2A. Let $L_{1}$ and $L_{2}$ be members of $\boldsymbol{L}$. Then the following statements are equivalent,

(i) $\quad L_{1} i^{\text {th }}$-degree upward dominates $L_{2}$

(ii) $\quad J_{P}\left(L_{1}\right)<J_{P}\left(L_{2}\right)$ for all $P \in \boldsymbol{P}_{1 i}^{*}$

(iii) $\quad J_{P}\left(L_{1}\right)<J_{P}\left(L_{2}\right)$ for all $P \in \boldsymbol{P}_{1 i}$ being such that $J_{P}$ obeys the principle of $(i-1)^{\text {th }}$-degree DPTS. (Proof in Appendix.)

THEOREM 3.2B. Let $L_{1}$ and $L_{2}$ be members of $\boldsymbol{L}$. Then the following statements are equivalent,

(i) $\quad L_{1} i^{\text {th }}$-degree downward dominates $L_{2}$

(ii) $\quad J_{P}\left(L_{1}\right)<J_{P}\left(L_{2}\right)$ for all $P \in \boldsymbol{P}_{2 i}^{*}$

(iii) $\quad J_{P}\left(L_{1}\right)<J_{P}\left(L_{2}\right)$ for all $P \in \boldsymbol{P}_{2 i}$ being such that $J_{P}$ obeys the principle of (i-1 $)^{\text {th }}$-degree UPTS 
The proof of Theorem 3.2B can be achieved by following the line of reasoning used in the proof of Theorem 3.2.A.

To characterize social preferences that are consistent with DPTS [UPTS] we adopt the following definition.

DEFINITION 3.5. A social decision-maker that supports the Pigou-Dalton principle of transfers and the principles of DPTS (UPTS) up to and including $i^{\text {th }}$-degree is said to exhibit downside (upside) positional inequality aversion of $i^{\text {th }}$-degree.

By adding the condition of dominating extended Gini coefficients $G_{k}$ for $k=1,2, \ldots, i-1$ to the condition of $\mathrm{i}^{\text {th }}$-degree upward Lorenz dominance it follows from the proof of Theorem 3.1A that the conditions $\mathrm{P}^{(\mathrm{j})}(1)=0, \mathrm{j}=2,3, \ldots, \mathrm{i}$ can be replaced by less restrictive conditions for $\mathrm{P}$, which means that the subfamily of $\mathrm{J}_{\mathrm{P}}$-measures that preserves a "restricted" $\mathrm{i}^{\text {th }}$-degree upward Lorenz dominance condition is larger than the subfamily of $\mathrm{J}_{\mathrm{p}}$-measures that preserves $\mathrm{i}^{\text {th }}$-degree upward Lorenz dominance. Moreover, as indicated above, the latter is a subfamily of the former. ${ }^{24}$

THEOREM 3.3A. Let $L_{1}$ and $L_{2}$ be members of $\boldsymbol{L}$. Then the following statements are equivalent,

(i) $\quad L_{1} i^{\text {th }}$-degree upward dominates $L_{2}$ and $G_{k}\left(L_{1}\right) \leq G_{k}\left(L_{2}\right)$ for $k=1,2, \ldots, i-1$

(ii) $\quad J_{P}\left(L_{1}\right)<J_{P}\left(L_{2}\right)$ for all $P \in \boldsymbol{P}_{1 i}^{* * *}$.

(Proof in Appendix.)

THEOREM 3.3B. Let $L_{1}$ and $L_{2}$ be members of $\boldsymbol{L}$. Then the following statements are equivalent,

(i) $\quad L_{1} i^{\text {th }}$-degree downward dominates $L_{2}$ and $D_{k}\left(L_{1}\right) \leq D_{k}\left(L_{2}\right)$ for $k=1,2, \ldots, i-1$

(ii) $\quad J_{P}\left(L_{1}\right)<J_{P}\left(L_{2}\right)$ for all $P \in \boldsymbol{P}_{2 i}^{* * *}$.

(Proof in Appendix.)

The proposed sequences of dominance criteria along with the results of Theorems 3.1A-3.3A and 3.1B-3.3B suggest two alternative strategies for increasing the number of Lorenz curves that can be strictly ordered by successively narrowing the class of inequality measures under consideration. As 
the dominance criteria of each sequence are nested these strategies also allow us to identify the value judgments that are needed to reach an unambiguous ranking of Lorenz curves. It follows from Theorem 3.2A that $\mathrm{J}_{\mathrm{P}}$-measures derived from P-functions with derivatives between second and $\mathrm{i}^{\text {th }}$ order that alternate in sign $\left((-1)^{\mathrm{j}-1} \mathrm{P}^{(\mathrm{j})}(\mathrm{t})>0, \mathrm{j}=2,3, \ldots, \mathrm{i}\right)$ preserve upward Lorenz dominance of all degrees lower than and equal to i-1. Thus, as demonstrated by Theorem 3.2A their sensitivity to changes that occur in the lower part of the income distribution (and the Lorenz curve) increases as $\mathrm{i}$ increases. By contrast, Theorem 3.2B shows that $\mathrm{J}_{\mathrm{P}}$-measures derived from P-functions with negative derivatives of order two and up to $\mathrm{i}\left(\mathrm{P}^{(\mathrm{j})}(\mathrm{t})<0, \mathrm{j}=2,3, \ldots, \mathrm{i}\right)$ preserve downward Lorenz dominance of all degrees lower than and equal to i-1. Theorem 3.2B demonstrates that this means that they increase their sensitivity to changes that occur in the upper part of the Lorenz curve as i increases. Note that the above theorems are only valid for finite $i$. At the extreme, as $i \rightarrow \infty$, observe that

$$
(i+1) ! L^{i+1}(u) \rightarrow \begin{cases}0, & 0 \leq u<1 \\ \frac{F^{-1}(0+)}{\mu}, & u=1\end{cases}
$$

and

$$
(i+1) ! \tilde{L}^{\tilde{i}^{+1}}(\mathrm{u}) \rightarrow \begin{cases}\frac{\mathrm{F}^{-1}(1)}{\mu}, & \mathrm{u}=0 \\ 0, & 0<\mathrm{u} \leq 1\end{cases}
$$

where $F^{-1}\left(0^{+}\right)$and $F^{-1}(1)$ denote the lowest and highest income, respectively. Hence, at the limit upward and downward Lorenz dominance solely depend on the income share of the worst-off and best-off income recipient, respectively. At the extreme upward Lorenz dominance is solely concerned with transfers that benefit the poorest unit. By contrast, downward Lorenz dominance solely focuses on transferring money from the richest to anyone else.

REMARK. Restricting the comparisons of Lorenz curves to distributions with equal means the various dominance results of Sections 2 and 3 are valid for generalized Lorenz curves and also apply to the so-called dual theory representation for choice under uncertainty introduced by Yaari (1988).

\footnotetext{
${ }^{24}$ Wang and Young (1998) provide a result similar to Theorem 3.3B for intersecting distribution functions. However, their result relies on the condition of negative derivatives (up to order i) of $\mathrm{P}$ whereas the condition for P used in Theorem 3.3B is less strict. Moreover, Wang and Young (1998) don't appear to be aware of the fact that their result concerns downward rather than upward inverse stochastic dominance.
} 


\section{SUMMARY AND DISCUSSION}

This paper introduces two sequences of partial orderings for achieving complete rankings of Lorenz curves. In particular, we have examined situations where Lorenz curves intersect by introducing various ranking criteria that are weaker than non-intersecting dominance (first-degree Lorenz dominance) and stronger than single measures of inequality. The proposed set of dominance criteria is shown to characterize nested subsets of the families of inequality measures defined by $\int \mathrm{P}^{\prime}(\mathrm{u}) \mathrm{d} \mathrm{L}(\mathrm{u})$ where $\mathrm{P}^{\prime}$ is the derivative of a function $\mathrm{P}$ that defines the inequality aversion profile of the inequality measure. The condition of first-degree Lorenz dominance corresponds to concave Pfunctions. By introducing higher degrees of dominance, this paper provides a method for identifying the lowest degree of dominance and the weakest restriction on the functional form of the preference function $\mathrm{P}$ that is needed to reach unambiguous rankings of Lorenz curves, irrespective of whether one's social preferences is consistent with downside or upside postional inequality aversion. To judge the normative significance of the sequences of dominance criteria, appropriate principles of transfers have been introduced. The set of Lorenz dominance criteria provides convenient computational methods for ranking a set of Lorenz curves and for exploring how robust the attained ranking would be with respect to choice of rank-dependent measures of inequality. Thus, in applied work the ranking obtained by applying this approach should in general have a wider degree of support than that obtained by applying arbitrarily chosen summary measures of inequality.

To deal with the mean income income inequality trade-off, in cases where they conflict, Shorrocks (1983) introduced the "generalized Lorenz curve”, defined as a mean scaled-up version of the Lorenz curve. Moreover, Shorrocks (1983) obtained characterizations of social welfare functions based on first-degree dominance relations between generalized Lorenz curves. Scaling up the introduced Lorenz dominance relations of this paper by the mean income $(\mu)$ and replacing the rankdependent measures of inequality $\mathrm{J}_{\mathrm{P}}$ defined by (2) with the rank-dependent social welfare functions $\mathrm{W}_{\mathrm{P}}=\mu\left(1-\mathrm{J}_{\mathrm{P}}\right)$, it can be demonstrated that the present results also apply to the generalized Lorenz curve and moreover provide convenient characterizations of the corresponding social welfare orderings. Accordingly, the obtained dominance and characterization results may e.g. form a helpful basis for exploring the robustness of empirically identified optimal tax and welfare regimes with respect to choice of rank-dependent welfare function and the corresponding degree of positional inequality aversion. Thus, the social evaluation framework proposed in this paper can be considered as an extension and improvement of the social evaluation methods that are based on selected measures of inequality from the Atkinson or the generalized Gini family of inequality measures. 


\section{APPENDIX}

\section{Proofs of Dominance Results}

LEMMA 1. Let $H$ be the family of bounded, continuous and non-negative functions on $[0,1]$ which are positive on $\{0,1\rangle$ and let $g$ be an arbitrary bounded and continuous function on [0,1]. Then

$$
\int g(t) h(t) d t>0 \text { for all } h \in H
$$

implies

$$
g(t) \geq 0 \text { for all } t \in[0,1]
$$

and the inequality holds strictly for at least one $t \in\langle 0,1\rangle$.

The proof of Lemma 1 is known from mathematical textbooks.

The proof of the equivalence between (i) and (ii) in Theorem 2.2A is analogous to the proof for stochastic dominance in Hadar and Russel (1969) but is included below for the sake of completeness.

Proof of Theorem 2.2A. Using integration by parts we have that

$$
\mathrm{J}_{\mathrm{P}}\left(\mathrm{L}_{2}\right)-\mathrm{J}_{\mathrm{P}}\left(\mathrm{L}_{1}\right)=-\mathrm{P}^{\prime \prime}(1) \int_{0}^{1}\left(\mathrm{~L}_{1}(\mathrm{u})-\mathrm{L}_{2}(\mathrm{u})\right) \mathrm{du}+\int_{0}^{1} \mathrm{P}^{\prime \prime \prime}(\mathrm{u}) \int_{0}^{\mathrm{u}}\left(\mathrm{L}_{1}(\mathrm{t})-\mathrm{L}_{2}(\mathrm{t})\right) \mathrm{dt} \mathrm{du} .
$$

Thus, if (i) holds then $\mathrm{J}_{\mathrm{P}}\left(\mathrm{L}_{2}\right)>\mathrm{J}_{\mathrm{P}}\left(\mathrm{L}_{1}\right)$ for all $\mathrm{P} \in \mathbf{P}_{12}^{*}$.

To prove the converse statement we restrict to preference functions $\mathrm{P} \in \mathbf{P}_{12}^{*}$. for which $\mathrm{P}^{\prime \prime}(1)=0$. Hence,

$$
\mathrm{J}_{\mathrm{P}}\left(\mathrm{L}_{2}\right)-\mathrm{J}_{\mathrm{P}}\left(\mathrm{L}_{1}\right)=\int_{0}^{1} \mathrm{P}^{\prime \prime \prime}(\mathrm{u}) \int_{0}^{\mathrm{u}}\left(\mathrm{L}_{1}(\mathrm{t})-\mathrm{L}_{2}(\mathrm{t})\right) \mathrm{dt} \mathrm{du}
$$

and the desired result it obtained by applying Lemma 1 .

To prove the equivalence between (ii) and (iii) consider a case where we transfer a small amount $\gamma$ from persons with incomes $\mathrm{F}^{-1}\left(\mathrm{~s}+\mathrm{h}_{1}\right)$ and $\mathrm{F}^{-1}\left(\mathrm{t}+\mathrm{h}_{1}\right)$ to persons with incomes $\mathrm{F}^{-1}(\mathrm{~s})$ and $\mathrm{F}^{-1}(\mathrm{t})$, respectively, where $\mathrm{t}$ is assumed to be larger than $\mathrm{s}$. Then $\mathrm{J}_{\mathrm{P}}$ defined by (2) obeys the firstdegree DPTS if and only if 


$$
\mathrm{P}^{\prime}(\mathrm{s})-\mathrm{P}^{\prime}\left(\mathrm{s}+\mathrm{h}_{1}\right)>\mathrm{P}^{\prime}(\mathrm{t})-\mathrm{P}^{\prime}\left(\mathrm{t}+\mathrm{h}_{1}\right)
$$

which for small $h_{1}$ is equivalent to

$$
\mathrm{P}^{\prime \prime}(\mathrm{t})-\mathrm{P}^{\prime}(\mathrm{s})>0
$$

Next, inserting for $t=s+h_{2}$, we find, for small $h_{2}$, that this is equivalent to $P^{\prime \prime \prime}(s)>0$.

The proof of Theorem 2.2B is analogous to the proof of Theorem 2.2A and is based on the expression

$$
\mathrm{J}_{\mathrm{P}}\left(\mathrm{L}_{2}\right)-\mathrm{J}_{\mathrm{P}}\left(\mathrm{L}_{1}\right)=-\mathrm{P}^{\prime \prime}(0) \int_{0}^{1}\left(\mathrm{~L}_{1}(\mathrm{t})-\mathrm{L}_{2}(\mathrm{t})\right) \mathrm{dt}-\int_{0}^{1} \mathrm{P}^{\prime \prime \prime}(\mathrm{u}) \int_{\mathrm{u}}^{1}\left(\mathrm{~L}_{1}(\mathrm{t})-\mathrm{L}_{2}(\mathrm{t})\right) \mathrm{dt} \mathrm{du}
$$

which is obtained by using integration by parts. Thus, by arguments like those in the proof of Theorem 2.2A the results of Theorem 2.2B are obtained.

Proof of Theorem 3.1A. To examine the case of $i^{\text {th }}$-degree upward Lorenz dominance we integrate $\mathrm{J}_{\mathrm{P}}\left(\mathrm{L}_{2}\right)-\mathrm{J}_{\mathrm{P}}\left(\mathrm{L}_{1}\right)$ by parts i times,

$$
\mathrm{J}_{\mathrm{P}}\left(\mathrm{L}_{2}\right)-\mathrm{J}_{\mathrm{P}}\left(\mathrm{L}_{1}\right)=\sum_{\mathrm{j}=2}^{\mathrm{i}}(-1)^{\mathrm{j}-1} \mathrm{P}^{(\mathrm{j})}(1)\left(\mathrm{L}_{1}^{\mathrm{j}}(1)-\mathrm{L}_{2}^{\mathrm{j}}(1)\right)+(-1)^{\mathrm{i}} \int_{0}^{1} \mathrm{P}^{(\mathrm{i}+1)}(\mathrm{u})\left(\mathrm{L}_{1}^{\mathrm{i}}(\mathrm{u})-\mathrm{L}_{2}^{\mathrm{i}}(\mathrm{u})\right) \mathrm{du}
$$

and use this expression in constructing the proof of the equivalence between (i) and (ii).

Assume first that (i) in Theorem 3.1A is true, i.e.

$$
\mathrm{L}_{1}^{\mathrm{i}}(\mathrm{u})-\mathrm{L}_{2}^{\mathrm{i}}(\mathrm{u}) \geq 0 \text { for all } \mathrm{u} \in[0,1]
$$

and $>$ holds for at least one $\mathrm{u} \in\langle 0,1\rangle$.

Then $\mathrm{J}_{\mathrm{P}}\left(\mathrm{L}_{2}\right)>\mathrm{J}_{\mathrm{P}}\left(\mathrm{L}_{1}\right)$ for all $\mathrm{P} \in \mathbf{P}_{1 \mathrm{i}}^{* *}$.

Conversely, assume that

$$
\mathrm{J}_{\mathrm{P}}\left(\mathrm{L}_{2}\right)>\mathrm{J}_{\mathrm{P}}\left(\mathrm{L}_{1}\right) \text { for all } \mathrm{P} \in \mathbf{P}_{1 \mathrm{i}}^{* *}
$$

For this family of preference functions we have that

$$
\mathrm{J}_{\mathrm{P}}\left(\mathrm{L}_{2}\right)-\mathrm{J}_{\mathrm{P}}\left(\mathrm{L}_{1}\right)=(-1)^{\mathrm{i}} \int_{0}^{1} \mathrm{P}^{(\mathrm{i}+1)}(\mathrm{u})\left(\mathrm{L}_{1}^{\mathrm{i}}(\mathrm{u})-\mathrm{L}_{2}^{\mathrm{i}}(\mathrm{u})\right) \mathrm{du}
$$

Then, as demonstrated by Lemma 1 , the desired result can be obtained by a suitable choice of $\mathrm{P} \in \mathbf{P}_{1 \mathrm{i}}^{* *}$. 
Proof of Theorem 3.2A. Assume that (i) in Theorem 3.2A is true, i.e.

$$
\mathrm{L}_{1}^{\mathrm{i}}(\mathrm{u})-\mathrm{L}_{2}^{\mathrm{i}}(\mathrm{u}) \geq 0 \text { for all } \mathrm{u} \in[0,1]
$$

and $>$ holds for at least one $u \in\langle 0,1\rangle$. Then it follows from Theorem 3.1A that $J_{P}\left(L_{2}\right)>J_{P}\left(L_{1}\right)$ for all $\mathrm{P} \in \mathbf{P}_{\mathrm{i} 1}$ such that $(-1)^{\mathrm{j}} \mathrm{P}^{(\mathrm{j}+1)}(\mathrm{t})>0$ for $\mathrm{t} \in\langle 0,1\rangle, \mathrm{j}=1,2, \ldots, \mathrm{i}$ since this family of P-functions is a subfamily of $\mathbf{P}_{1 \mathrm{i}}^{* *}$.

Conversely, assume that $\mathrm{J}_{\mathrm{P}}\left(\mathrm{L}_{2}\right)>\mathrm{J}_{\mathrm{P}}\left(\mathrm{L}_{1}\right)$ for all $\mathrm{P} \in \mathbf{P}_{1 \mathrm{i}}$ such that $(-1)^{j} \mathrm{P}^{(j+1)}(\mathrm{t})>0$ for $\mathrm{t} \in\langle 0,1\rangle, \mathrm{j}=1,2, \ldots, \mathrm{i}$. For this family of P-functions we have that

$$
\mathrm{J}_{\mathrm{P}}\left(\mathrm{L}_{2}\right)-\mathrm{J}_{\mathrm{P}}\left(\mathrm{L}_{1}\right)=(-1)^{\mathrm{i}} \int_{0}^{1} \mathrm{P}^{(\mathrm{i}+1)}(\mathrm{u})\left(\mathrm{L}_{1}^{\mathrm{i}}(\mathrm{u})-\mathrm{L}_{2}^{\mathrm{i}}(\mathrm{u})\right) \mathrm{du}
$$

and the desired result is obtained by applying Lemma 1 .

A proof by mathematical induction will be used to prove the equivalence between (ii) and (iii). To this end it is convenient to introduce the following notation. Let $\mathrm{H}_{1}, \mathrm{H}_{2}$ and $\mathrm{H}_{\mathrm{j}+1}$ be defined by

$$
\begin{gathered}
\mathrm{H}_{1}\left(\mathrm{v}, \mathrm{h}_{1}\right)=\mathrm{P}^{\prime}(\mathrm{v})-\mathrm{P}^{\prime}\left(\mathrm{v}+\mathrm{h}_{1}\right), \\
\mathrm{H}_{2}\left(\mathrm{~s}, \mathrm{t}, \mathrm{h}_{1}\right)=\mathrm{H}_{1}\left(\mathrm{~s}, \mathrm{~h}_{1}\right)-\mathrm{H}_{1}\left(\mathrm{t}, \mathrm{h}_{1}\right)
\end{gathered}
$$

and

$$
H_{j+1}\left(s, t, h_{1}, h_{2}, \ldots, h_{j}\right)=H_{j}\left(s, t, h_{1}, h_{2}, \ldots, h_{j-1}\right)-H_{j}\left(s+h_{j}, t+h_{j}, h_{1}, h_{2}, \ldots, h_{j-1}\right), j=2,3, \ldots
$$

Moreover, let

$$
\mathrm{H}_{2}^{(1)}(\mathrm{s}, \mathrm{t})=\lim _{\mathrm{h}_{1} \rightarrow 0} \frac{1}{\mathrm{~h}_{1}} \mathrm{H}_{2}\left(\mathrm{~s}, \mathrm{t}, \mathrm{h}_{1}\right)
$$

and

$$
\mathrm{H}_{\mathrm{j}+1}^{(\mathrm{j})}(\mathrm{s}, \mathrm{t})=\lim _{\mathrm{h}_{\mathrm{j}} \rightarrow 0} \ldots \lim _{\mathrm{h}_{1} \rightarrow 0} \frac{1}{\prod_{\mathrm{k}=1}^{\mathrm{j}} \mathrm{h}_{\mathrm{k}}} \mathrm{H}_{\mathrm{j}+1}\left(\mathrm{~s}, \mathrm{t}, \mathrm{h}_{1}, \mathrm{~h}_{2}, \ldots, \mathrm{h}_{\mathrm{j}}\right) .
$$

It follows from Theorems 2.1 and 2.2A that $\mathrm{J}_{\mathrm{P}}$ obeys the Pigou-Dalton principle of transfers and the first-degree DPTS iff $\mathrm{P}^{\prime \prime}(\mathrm{t})<0$ and $\mathrm{P}^{\prime \prime \prime}(\mathrm{t})>0$. From (13), definition (2) of $\mathrm{J}_{\mathrm{P}}$ and (A2)-(A6) we then get that $\mathrm{J}_{\mathrm{P}}$ obeys the second-degree DPTS iff 


$$
\mathrm{H}_{3}^{(2)}(\mathrm{s}, \mathrm{t})>0 \text { for } \mathrm{s}<\mathrm{t}
$$

Inserting for (A4), (A3) and (A2) in (A6) for $\mathrm{j}=2$ yields

$$
\begin{aligned}
& \mathrm{H}_{3}^{(2)}(\mathrm{s}, \mathrm{t})=\lim _{\mathrm{h}_{2} \rightarrow 0} \lim _{\mathrm{h}_{1} \rightarrow 0} \frac{1}{\mathrm{~h}_{1} \mathrm{~h}_{2}} \mathrm{H}_{3}\left(\mathrm{~s}, \mathrm{t}, \mathrm{h}_{1}, \mathrm{~h}_{2}\right)= \\
& \lim _{\mathrm{h}_{2} \rightarrow 0} \lim _{\mathrm{h}_{1} \rightarrow 0} \frac{1}{\mathrm{~h}_{1} \mathrm{~h}_{2}}\left(\mathrm{H}_{2}\left(\mathrm{~s}, \mathrm{t}, \mathrm{h}_{1}\right)-\mathrm{H}_{2}\left(\mathrm{~s}+\mathrm{h}_{2}, \mathrm{t}+\mathrm{h}_{2}, \mathrm{~h}_{1}\right)\right)= \\
& \lim _{\mathrm{h}_{2} \rightarrow 0} \frac{1}{\mathrm{~h}_{2}}\left(\mathrm{H}_{2}^{(1)}(\mathrm{s}, \mathrm{t})-\mathrm{H}_{2}^{(1)}\left(\mathrm{s}+\mathrm{h}_{2}, \mathrm{t}+\mathrm{h}_{2}\right)\right)= \\
& \lim _{\mathrm{h}_{2} \rightarrow 0} \frac{1}{\mathrm{~h}_{2}} \lim \frac{1}{\mathrm{~h}_{1}}\left\{\mathrm{P}^{\prime}(\mathrm{s})-\mathrm{P}^{\prime}\left(\mathrm{s}+\mathrm{h}_{1}\right)-\left(\mathrm{P}^{\prime}(\mathrm{t})-\mathrm{P}^{\prime}\left(\mathrm{t}+\mathrm{h}_{1}\right)\right)-\right. \\
& \left.\left[\mathrm{P}^{\prime}\left(\mathrm{s}+\mathrm{h}_{2}\right)-\mathrm{P}^{\prime}\left(\mathrm{s}+\mathrm{h}_{1}+\mathrm{h}_{2}\right)-\left(\mathrm{P}^{\prime}\left(\mathrm{t}+\mathrm{h}_{2}\right)-\mathrm{P}^{\prime}\left(\mathrm{t}+\mathrm{h}_{1}+\mathrm{h}_{2}\right)\right)\right]\right\}= \\
& \lim _{\mathrm{h}_{2} \rightarrow 0} \frac{1}{\mathrm{~h}_{2}}\left[-\mathrm{P}^{\prime \prime}(\mathrm{s})+\mathrm{P}^{\prime \prime}\left(\mathrm{s}+\mathrm{h}_{2}\right)-\left(-\mathrm{P}^{\prime \prime}(\mathrm{t})-\mathrm{P}^{\prime \prime}\left(\mathrm{t}+\mathrm{h}_{2}\right)\right)\right]=\mathrm{P}^{(3)}(\mathrm{s})-\mathrm{P}^{(3)}(\mathrm{t}) .
\end{aligned}
$$

Inserting for $\mathrm{t}=\mathrm{s}+\mathrm{h}$, we find, for small $\mathrm{h}$, that this is equivalent to $\mathrm{P}^{(4)}(\mathrm{s})<0$.

Next, assume that

$$
\mathrm{H}_{\mathrm{j}}^{(\mathrm{j}-1)}(\mathrm{s}, \mathrm{t})=(-1)^{\mathrm{j}-1}\left(\mathrm{P}^{(\mathrm{j})}(\mathrm{s})-\mathrm{P}^{(\mathrm{j})}(\mathrm{t})\right)
$$

It follows from Theorem 2.2A and the proof above that (A8) is true for $\mathrm{j}$ equal to 2 and 3.

Inserting for (A4) in (A6) we get

$$
\begin{aligned}
& \mathrm{H}_{\mathrm{j}+1}^{(\mathrm{j})}(\mathrm{s}, \mathrm{t})=1 \lim _{\mathrm{h}_{\mathrm{j}} \rightarrow 0} \ldots \lim _{\mathrm{h}_{1} \rightarrow 0} \frac{1}{\prod_{\mathrm{k}=1}^{\mathrm{j}} \mathrm{h}_{\mathrm{k}}}\left(\mathrm{H}_{\mathrm{j}}\left(\mathrm{s}, \mathrm{t}, \mathrm{h}_{1}, \mathrm{~h}_{2}, \ldots, \mathrm{h}_{\mathrm{j}-1}\right)-\mathrm{H}_{\mathrm{j}}\left(\mathrm{s}+\mathrm{h}_{\mathrm{j}}, \mathrm{t}+\mathrm{h}_{\mathrm{j}}, \mathrm{h}_{1}, \mathrm{~h}_{2}, \ldots, \mathrm{h}_{\mathrm{j}-1}\right)\right)= \\
& \lim _{\mathrm{h}_{\mathrm{j}} \rightarrow 0} \ldots \lim _{\mathrm{h}_{2} \rightarrow 0} \frac{1}{\prod_{\mathrm{k}=2}^{\mathrm{j}} \mathrm{h}_{\mathrm{k}}}\left(\mathrm{H}_{\mathrm{j}}^{(1)}\left(\mathrm{s}, \mathrm{t}, \mathrm{h}_{2}, \mathrm{~h}_{3}, \ldots, \mathrm{h}_{\mathrm{j}-1}\right)-\mathrm{H}^{(1)}\left(\mathrm{s}+\mathrm{h}_{\mathrm{j}}, \mathrm{t}+\mathrm{h}_{\mathrm{j}}, \mathrm{h}_{2}, \mathrm{~h}_{3}, \ldots, \mathrm{h}_{\mathrm{j}-1}\right)\right)= \\
& \lim _{\mathrm{h}_{\mathrm{j}} \rightarrow 0} \frac{1}{\mathrm{~h}_{\mathrm{j}}}\left(\mathrm{H}_{\mathrm{j}}^{(\mathrm{j}-1)}(\mathrm{s}, \mathrm{t})-\mathrm{H}_{\mathrm{j}}^{(\mathrm{j}-1)}\left(\mathrm{s}+\mathrm{h}_{\mathrm{j}}, \mathrm{t}+\mathrm{h}_{\mathrm{j}}\right)\right),
\end{aligned}
$$

which by inserting for (A8) yields

$$
\mathrm{H}_{\mathrm{j}+1}^{(\mathrm{j})}(\mathrm{s}, \mathrm{t})=(-1)^{\mathrm{j}}\left(\mathrm{P}^{(\mathrm{j}+1)}(\mathrm{s})-\mathrm{P}^{(\mathrm{j}+1)}(\mathrm{t})\right)
$$

Thus, (A8) is proved to be true by induction.

Since $\mathrm{J}_{\mathrm{P}}$ defined by (2) obeys the $(\mathrm{i}-1)^{\mathrm{th}}$-degree DPTS if and only if

$$
\mathrm{H}_{\mathrm{i}}^{(\mathrm{i}-1)}(\mathrm{s}, \mathrm{t})>0 \text { for } \mathrm{s}<\mathrm{t}
$$


we get from (A8) that this condition is equivalent to

$$
(-1)^{\mathrm{i}} \mathrm{P}^{(\mathrm{i}+1)}(\mathrm{s})>0
$$

Proof of Theorem 3.3A. By inserting for (8) in (A1) we get that

$$
J_{P}\left(L_{2}\right)-J_{P}\left(L_{1}\right)=\sum_{j=2}^{i}(-1)^{j-1} P^{(j)}(1)\left(G_{j-1}\left(L_{2}\right)-G_{j-1}\left(L_{1}\right)\right)+(-1)^{i} \int_{0}^{1} P^{(i+1)}(u)\left(L_{1}^{i}(u)-L_{2}^{i}(u)\right) d u \text {.(A9) }
$$

Assume first that (i) of Theorem 3.3A is true. Then $\mathrm{J}_{\mathrm{P}}\left(\mathrm{L}_{2}\right)>\mathrm{J}_{\mathrm{P}}\left(\mathrm{L}_{1}\right)$ for all $\mathrm{P} \in \mathbf{P}_{1 i}^{* * *}$.

Conversely, assume that

$$
\mathrm{J}_{\mathrm{P}}\left(\mathrm{L}_{2}\right)>\mathrm{J}_{\mathrm{P}}\left(\mathrm{L}_{1}\right) \text { for all } \mathrm{P} \in \mathbf{P}_{1 \mathrm{i}}^{* * *} \text {. }
$$

Then this statement holds for the subfamily of $\mathbf{P}_{1 i}^{* * *}$ for which $P^{(j)}(1)=0$ for $j=2,3, \ldots, i$. For this particular family of preference functions we get that

$$
\mathrm{J}_{\mathrm{P}}\left(\mathrm{L}_{2}\right)-\mathrm{J}_{\mathrm{P}}\left(\mathrm{L}_{1}\right)=(-1)^{\mathrm{i}} \int_{0}^{1} \mathrm{P}^{(\mathrm{i}+1)}(\mathrm{u})\left(\mathrm{L}_{1}^{\mathrm{i}}(\mathrm{u})-\mathrm{L}_{2}^{\mathrm{i}}(\mathrm{u})\right) \mathrm{du}
$$

By applying Lemma 1 we get that $\mathrm{L}_{1} \mathrm{i}^{\text {th }}$-degree upward dominates $\mathrm{L}_{2}$.

Next, consider the subfamily of preference functions defined by

$$
P_{k}(t)=1-(1-t)^{k+1}, \quad k=1,2, \ldots, i-1
$$

By observing that $\mathrm{P}_{\mathrm{k}} \in \mathbf{P}_{1 \mathrm{i}}^{* * * *}$ we find by inserting for (A10) in $\mathrm{J}_{\mathrm{P}}$ that

$$
0<\mathrm{J}_{\mathrm{P}_{\mathrm{k}}}\left(\mathrm{L}_{2}\right)-\mathrm{J}_{\mathrm{P}_{\mathrm{k}}}\left(\mathrm{L}_{1}\right)=\mathrm{G}_{\mathrm{k}}\left(\mathrm{L}_{2}\right)-\mathrm{G}_{\mathrm{k}}\left(\mathrm{L}_{1}\right)
$$

for $\mathrm{k}=1,2, \ldots, \mathrm{i}-1$.

The proofs of Theorems 3.1B, 3.2B and 3.3B can be constructed by following exactly the line of reasoning used in the proofs of Theorems 3.1A and 3.3A. The proofs use the following expression,

$$
\mathrm{J}_{\mathrm{P}}\left(\mathrm{L}_{2}\right)-\mathrm{J}_{\mathrm{p}}\left(\mathrm{L}_{1}\right)=-\sum_{\mathrm{j}=2}^{\mathrm{i}} \mathrm{P}^{(\mathrm{j})}(0)\left(\tilde{\mathrm{L}}_{2}^{\mathrm{j}}(0)-\tilde{\mathrm{L}}_{1}^{\mathrm{j}}(0)\right)-\int_{0}^{1} \mathrm{P}^{(\mathrm{i}+1)}(\mathrm{u})\left(\tilde{\mathrm{L}}_{2}^{\mathrm{i}}(\mathrm{u})-\tilde{\mathrm{L}}_{1}{ }^{\mathrm{i}}(\mathrm{u})\right) \mathrm{du},
$$

which is obtained by using integration by parts i times. 


\section{REFERENCES}

Aaberge, R. (2000): Characterizations of Lorenz curves and income distributions, Social Choice and Welfare, 17, 639-653.

Aaberge, R. (2001): Axiomatic characterization of the Gini coefficient and Lorenz curve orderings, Journal of Economic Theory, 101, 115-132.

Atkinson, A.B. (1970): On the measurement of inequality, Journal of Economic Theory, 2, 244-263.

Atkinson, A.B. (2007): More on the measurement of inequality, Journal of Economic Inequality, 6, 277-283.

Atkinson, A.B., L. Rainwater and T. Smeeding (1995): "Income Distribution in OECD Countries: The Evidence from the Luxembourg Income Study (LIS)”, Social Policy Studies No. 18, OECD, Paris.

Bossert, W. (1990): An approximation of the single-series Ginis, Journal of Economic Theory, 50, 8292.

Chateauneuf, A., T. Gajdos and P.-H. Welthien (2002): The principle of strong diminishing transfers, Journal of Economic Theory, 103, 311-333.

Chew, S.H. (1983): A generalization of the quasilinear mean with applications to the measurement of inequality and decision theory resolving the Allais paradox, Econometrica, 51 (1983), 1065-1092.

Chiu, H. W. (2007): Intersecting Lorenz curves, the degree of downside inequality aversion, and tax reforms, Social Choice and Welfare, 28, 375-399.

Cowell, F.A. (1977): “Measuring Inequality”, Deddington, Philip Allan.

Dardanoni, V. and P.J. Lambert (1988): Welfare rankings of income distributions: A role for the variance and some insights for tax reforms, Social Choice and Welfare, 5, 1-17.

Davies, J.B. and M. Hoy (1995): Making inequality comparisons when Lorenz curves intersect, American Economic Review, 85, 980-986.

Donaldson, D. and J.A. Weymark (1980): A single parameter generalization of the Gini indices of inequality, Journal of Economic Theory, 22, 67-86.

Ebert, U. (1987): Size and distribution of incomes as determinants of social welfare, Journal of Economic Theory, 41, 23-33.

Fields, G.E. and J.C.H. Fei (1978): On inequality comparisons, Econometrica, 46, 303-316.

Fishburn, P.C. and R.D. Willig (1984): Transfer principles in income distribution, Journal of Public Economics, 25, 323-328.

Giaccardi, F. (1950): Un criterio per la construzione di indici di conzentrazione, Rivista Italiana di Demografia e Statistica, 4, 527-538.

Hadar, J. and W. Russel (1969): Rules for ordering uncertain prospects, American Economic Review, 59, 25-34.

Hardy, G.H., J.E. Littlewood and G. Polya (1934): "Inequalities”, Cambridge University Press, Cambridge. 
Kolm, S.Ch. (1969): The optimal production of social justice, in "Public Economics”, (J. Margolis and H. Guitton, Eds.), Macmillan, New York/London.

Kolm, S.Ch. (1976): Unequal inequalities I, Journal of Economic Theory, 12, 416-442.

Lambert, P.J. (1985): Social welfare and the Gini coefficient revisited, Mathematical Social Sciences, 9, 19-26.

Lambert, P.J. (1993a): "The Distribution and Redistribution of Income: A Mathematical Analysis”, Manchester University Press, Manchester.

Lambert, P.J. (1993b): Evaluating impact effects of tax reforms, Journal of Economic Surveys, 7, 205242.

Mehran, F. (1976): Linear measures of inequality, Econometrica 44, 805-809.

Moffitt, R. A. (2003): The negative income tax and the evolution of U. S. welfare policy, Journal of Economic Perspectives 17, 119 - 140.

Muliere, P. and M. Scarsini (1989): A note on stochastic dominance and inequality measures, Journal of Economic Theory, 49, 314-323.

Piesch, W. (1975): “Statistische Konzentrationsmasse”, Mohr (Siebeck), Tübingen.

Sen, A. (1992): “Inequality Reexamined”, Clarendon Press, Oxford.

Shorrocks, A.F. (1983): Ranking income distributions, Economica, 50, 3-17.

Shorrocks, A.F. and J.E. Foster (1987): Transfer sensitive inequality measures, Review of Economic Studies, 14, 485-497.

Smith, A. (1979): “An Inquiry into the Nature and Causes of the Wealth of Nations”, Clarendon Press, Oxford.

Wang, S.S. and V.R. Young (1998): Ordering risks: Expected utility theory versus Yaari's dual theory of risk, Insurance: Mathematics and Economics, 22, 145-161.

Weymark, J. (1981): Generalized Gini inequality indices, Mathematical Social Sciences, 1, 409-430.

Whitmore, G. (1970): Third-degree stochastic dominance, American Economic Review, 60, 457-459.

Yaari, M.E. (1988): A controversial proposal concerning inequality measurement, Journal of Economic Theory, 44, 381-397.

Yitzhaki, S. (1983): On an extension of the Gini inequality index, International Economic Review, 24, 617-628.

Zoli, C. (1999): Intersecting generalized Lorenz curves and the Gini index, Social Choice and Welfare, 16, 183-196.

Zoli, C. (2002): Inverse stochastic dominance, inequality measurement and Gini indices, Journal of Economics Supplement, 9, 119-161. 